\title{
NUMERICAL ANALYSIS OF SQUARE HOLLOW COLUMN-BEAM CONNECTIONS BY ABAQUS
}

\author{
Moussa TWIZERE ${ }^{1}$ (D) , Kivanç TAŞKIN ${ }^{1, *}$ \\ ${ }^{1}$ Department of Civil Engineering, Engineering Faculty, Eskisehir Technical University, Eskisehir, Turkey
}

\begin{abstract}
In recent years, steel or composite beam-column connections have drawn increasing praise due to the rapid development of assembled steel structures. However, limited researches have paid attention to the analytical behaviour of square hollow column-beam joints. This work presents a numerical study on the static and cyclic behaviour of the connections between a square hollow steel column and I-beam. Finite element analytical modeling of the joint was performed considering complex contact interactions and material models. Six different connections were evaluated by using ABAQUS. The modeling techniques used in this work, including the mesh and element types, the material properties, and the contact elements, were validated by comparing the numerical results of a through plate connection model with the experimental study results. Good agreement between the test and analytical results was observed in terms of the failure modes and the hysteretic behaviour. The failure mode, moment-rotation curves for hollow steel section (HSS) column to steel beam connections were discussed based on numerical results.
\end{abstract}

Keywords: Numerical study, Hollow column; I-beam, Through plate, Cyclic loading

\section{INTRODUCTION}

Hallow square columns are very popular due to their superior resistance and aesthetic appeal. In modern steel construction HSS can be connected to I-beam through single plate connection (shear tab), double angle shear connection the plate, or direct weld beam to the column. Connection of HSS column is one of the most critical challenging components of HSS structural system. In recent years several HSS column-beam connection has been evaluated, new hybrid connections have also been suggested [1-7].

The steel beam can be simply connected to the steel tube skin for quick connection [8]. However, Alostaz and Schneider [9] have shown that the beam's welding directly to the steel tube should be avoided in a moment resistance frame. This welding is due to the tube wall's severe distortions, which prevent the creation of the plastic hinge in the beam. Kosteski and Packer [10] introduced a plate connection in which the plate passed through both walls of the HSS member first and was then welded to the slotted tube. Hoang et al. [11] introduced a vertical plate to support the primary beam through plate-to-concrete hollow steel (CHS) column connection. Two horizontal plates, one at each side of the CHS, were welded to the upper side of the through-plate to facilitate the connection. Jiang and Chen [5] proposed an innovative connection known as double-through plate connection. Two plates pass through a slotted square column with the concrete infill; this connection could limit the plastic hinge in the panel zone.

This work numerically investigated the performance of six different HSS column- beam connections (Figure 1). Three connections direct welded to the column (Figure $1 \mathrm{a}-\mathrm{c}$ ), and three through plate connections (Figure $1 \mathrm{~d}-\mathrm{e}$ ) were examined. Specimens were evaluated under static and cyclic loading.

*Corresponding Author: kivanct@eskisehir.edu.tr

Received: 25.01.2021 Published: 26.10.2021 
The relevant numerical results were shown in detail. Based on the verified models, several parameters influencing the connection response were analyzed. And finally, the behaviours of the connection were summarized.

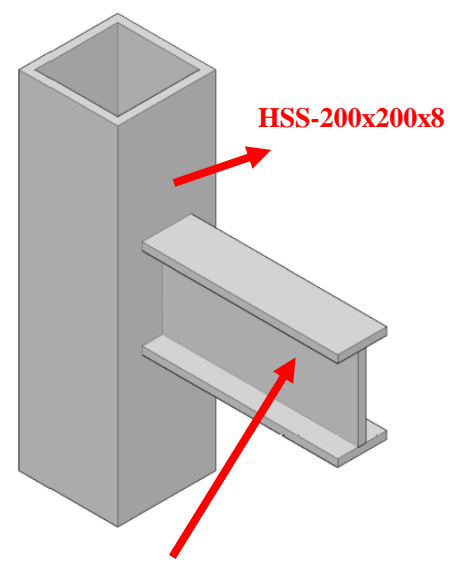

IPE-200

a) Model-1
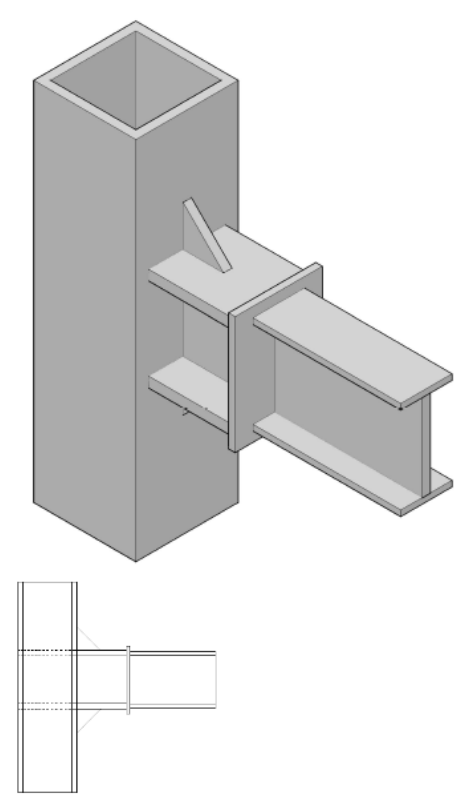

d) Model-4

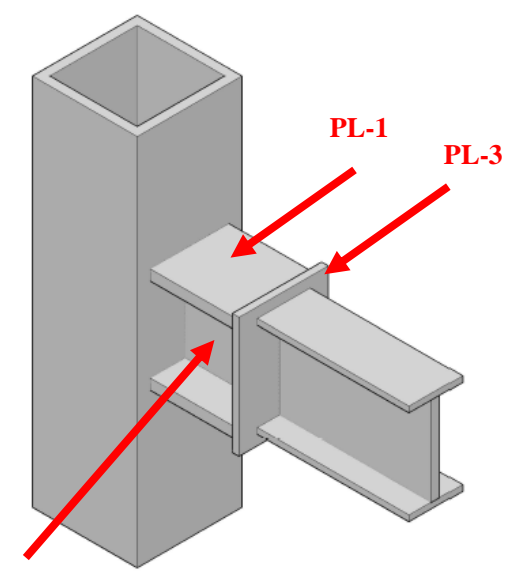

PL-2

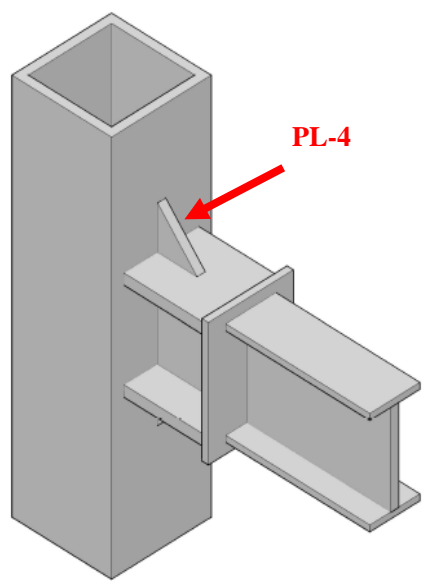

c) Model-3

Figure 1. Connection configuration

Table 1. Dimension of elements

\begin{tabular}{cccc}
\hline Column & HS200x200x8 & Beam & IPE-200 \\
\hline PL-1 & PL410x140x20 & PL-2 & PL171.5x200x20 \\
\hline PL-3 & PL200x171.5x20 & PL-4 & $1 / 2$ P100x100x20 \\
\hline PL-5 & PL100x100x20 & PL-6 & PL140x200x20 \\
\hline
\end{tabular}

Table 2. Material properties [11]

\begin{tabular}{lccc}
\hline Class & $\begin{array}{c}\text { Yield } \\
\text { stress } \\
(\mathbf{M P a})\end{array}$ & $\begin{array}{c}\text { ultimate } \\
\text { stress } \\
(\mathbf{M P a})\end{array}$ & $\begin{array}{c}\text { Young's } \\
\text { modulus } \\
(\mathbf{G P a})\end{array}$ \\
\hline S275 & 275 & 430 & 210000 \\
\hline S355 & 355 & 490 & 210000 \\
\hline
\end{tabular}




\section{CONNECTION DESIGN}

Six different connections between the mid-height of HSS-column of the two adjacent floors and a halfspan of the beam were designed to simulate an exterior T-shaped joint subassembly. I-beam (IPE-200) was connected to a square hollow steel column (SHS 200X8). This connection was intended to follow the strong column weak beam's rule by the length was $3000 \mathrm{~mm}$ and $2500 \mathrm{~mm}$ for column and beam, respectively. The studied connection was named Model-1 to Model-6. Model-1, Model-2, and Model3 were directly welded to the column, Model-4, Model-5, and Model- 6 columns were connected to the beam through plate connection. Table 1 shows the dimension properties of elements used in the modeling of the connection. The materials were assumed to be S355 for the column and S275 for the plate. The yield stress, ultimate stress, and young modulus are shown in Table 2.

\section{FINITE ELEMENT MODELLING}

\subsection{General}

Beam column connection modeling with Finite element-based software such as ANSYS and ABAQUS has gained popularity in recent years. It was proved that this software could accurately predict the behavior of simple or complex connections [11] - [15]. This study focuses on analytical modeling using ABAQUS software. FE accuracy depends on the materials model, mesh types and size, boundary conditions, and contact element. Reduced integration element (C3D8R) type of meshing was adopted for the analyses. This element uses a lower-order integration element to establish the element stiffness matrix. The choice of reduced integration element was considered to reduce the computational cost of the executed FE models. The structured meshing technique was adopted to have an appropriate element shape. Fine mesh size was used at the connection vicinity while the dimension was coarse by moving away from the panel zone.

\subsection{Material Modeling}

The constitutive behaviour of steel was described by an elastic-plastic model that considers Von Mises yield criteria. The mixed hardening model was applied for the steel. This model also accounts for the well-known Bauschinger effect for steel under cyclic loading, which is characterized by reduced yield stress upon load reversal after plastic deformation has occurred. ABAQUS is expected to take actual stress and true strain. Equations (1) and (2) were used to convert the normal stress and nominal strain to true stress and true strain.

$$
\begin{gathered}
\sigma_{\text {true }}=\sigma_{\text {nominal }}\left(1+\varepsilon_{\text {nominal }}\right) \\
\varepsilon_{\text {true }}=\ln \left(1+\varepsilon_{\text {nominal }}\right)
\end{gathered}
$$

\subsection{Modeling of the Contact Element and Boundary Condition}

To the Model, the contact of parts ABAQUS offers interaction and constraint [16]. The interaction properties that allow tangential behaviour with the penalty and normal behaviour were considered. Zhang et al. refer to the divergent behaviour of friction coefficient of 0.45 were used for all interaction. For normal behaviour, hard contact allows separation after a connection was adopted. To assign the contact properties for only the targeted surface, all elements in contact were well portioned. ABAQUS provides a surface-to-surface contact and node-to-node contact. To accurately resolve the connection of parts surface to surface contact was used instead of node-to-node contact. To avoid the premature termination, which may be caused by penetrations, master and slave surfaces must be well defined. The slave surface node cannot penetrate the master surface though the master surface can. For that, the master surface must be stiffer than the slave surface [17]. In case two elements the same material properties master surface is the one with coarse mesh. 
Columns were pinned at the top and the bottom. In the model's pinned support, two rigid plates were connected at both ends of the column. To apply load and eliminate stress concentration at the loading area, a rigid plate was tied at the end of the beam. Also, lateral support was provided to restrict bending in a direction other than a loading direction. The nonlinear effects of large displacement were also taken into account. The damping factor of 0.0002 was introduced to solve the convergence problem. In this study, the SAC loading protocol was followed (see Figure 2).

\begin{tabular}{|r|r|r|r|c|}
\hline $\begin{array}{c}\text { Load } \\
\text { step } \\
\text { number }\end{array}$ & $\begin{array}{c}\text { Interstory } \\
\text { drift angle } \\
\text { (rad) }\end{array}$ & $\begin{array}{c}\text { Number } \\
\text { of loading } \\
\text { cycles }\end{array}$ \\
\hline 1 & 0.00375 & 6 \\
\hline 2 & 0.005 & 6 \\
\hline 3 & 0.0075 & 6 \\
\hline 4 & 0.01 & 4 \\
\hline 5 & 0.015 & 2 \\
\hline 6 & 0.2 & 2 \\
\hline 7 & 0.3 & 2 \\
\hline 8 & 0.4 & 2 & 2 \\
\hline 9 & 0.5 & 2 &
\end{tabular}

Figure 2. SAC loading protocol loading protocol

\subsection{Finite Element Modeling Verification}

To verify the accuracy of numerical model responses, an experimental I-beam to box column connection model by Gholami 2013 [18] was modeled in ABAQUS. Gholami experimentally studies T-shaped large-scale specimens. The geometrical assembly is shown in (Figure 3). The sample was constructed with an I-380 $\times 200 \times 8 \times 12(\mathrm{~mm})$ beam and a built-up B-400 $\times 400 \times 20 \times 20(\mathrm{~mm})$ box column. The length was $3000 \mathrm{~mm}$ and $2500 \mathrm{~mm}$, respectively The gap between column and beam was $20 \mathrm{~mm}$. American Institute of Steel Connection (AISC) seismic Loading protocol was used. The young modulus was $200 \mathrm{GPa}$. 


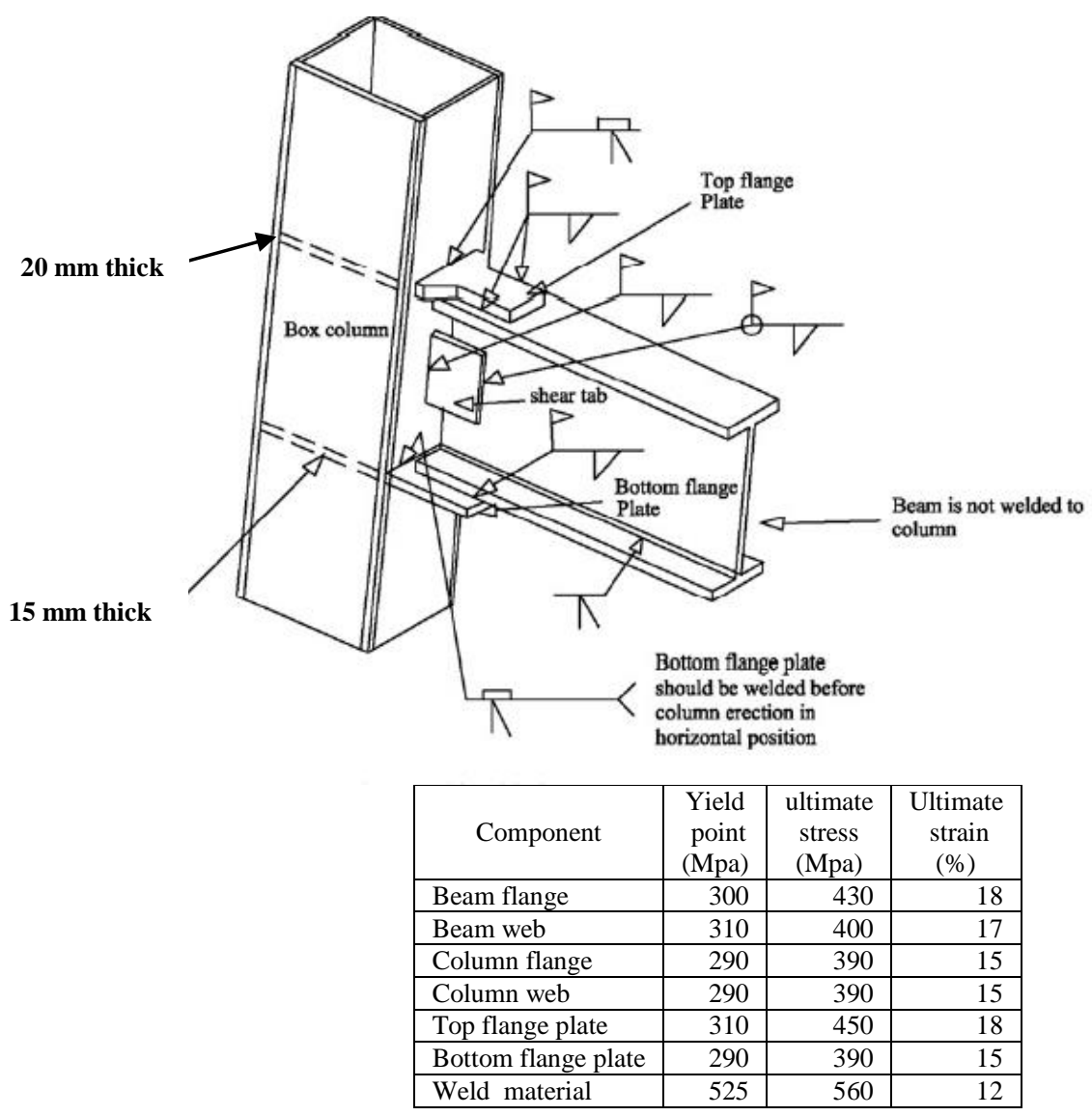

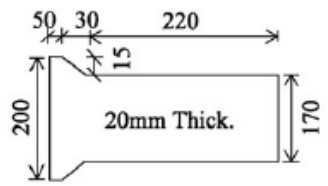

Top reinforcing plate

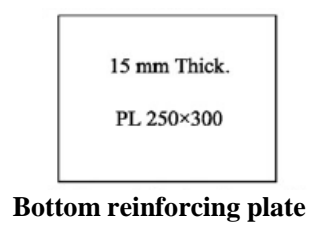

Figure 3. Gholami geometrical configuration Hata! Başvuru kaynağı bulunamadı.

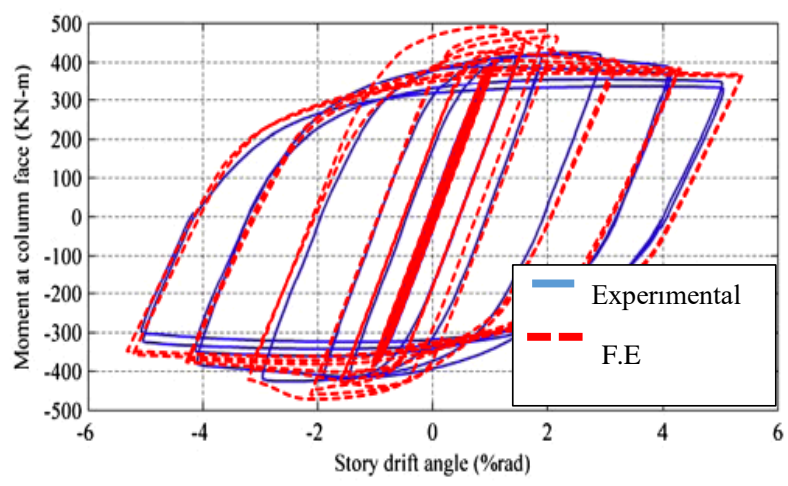

Figure 4. Comparison of experimental Hata! Başvuru kaynağı bulunamadı. and simulated FEM models

The moment rotation curve of Gholami was compared to the Finite element model, the accuracy of the proposed model was found to be good (see Figure 4). Also, the accuracy of the failure mode of the specimens was found. Figure 5 compares the failure mode of the experimental and simulated finite element model. The plastic hinge formation was found to be at the exact location for both testing and numerical models. 

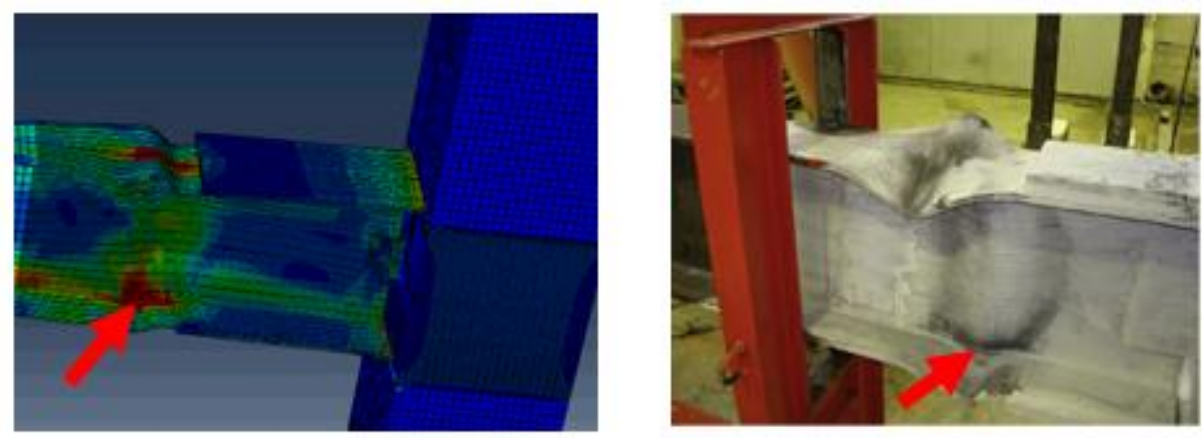

Figure 5. Comparison of the experimental Hata! Başvuru kaynağı bulunamadı. and numerical plastic hinge formation in the connecting beam

\section{NUMERICAL RESULTS}

\subsection{Moment Rotation Curve}

Figure 6 and Figure 7 show the moment rotation curve of all specimens. Model-1, Model-2, and Model3 had an initial stiffness less than Model-4, Model-5, and Model-6; this is due to the inclusion of through plate. To reach the beam's plastic capacity, specimens without through plate carry up excessive rotation till 0.4. Direct welding beam to column had less initial stiffness than other models where the beam was connected to the column by plate. For through plate connection, stiffeners' inclusion increases the moment capacity of the connection; however, the initial stiffness remains almost the same.

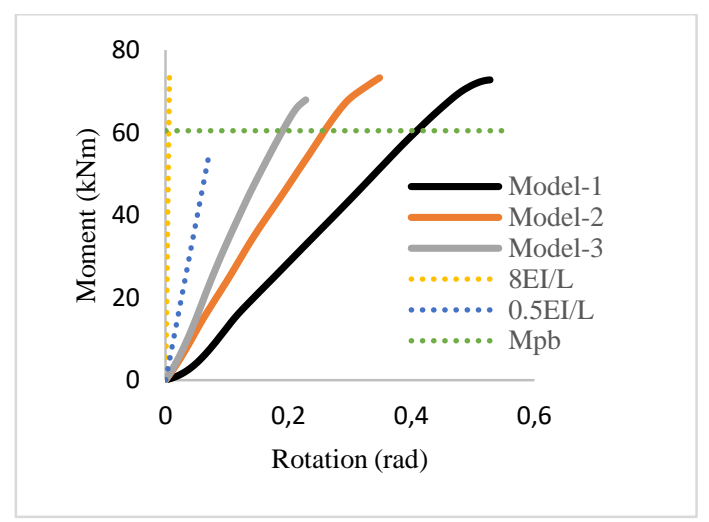

Figure 6. Moment rotation curve of specimens without through plate

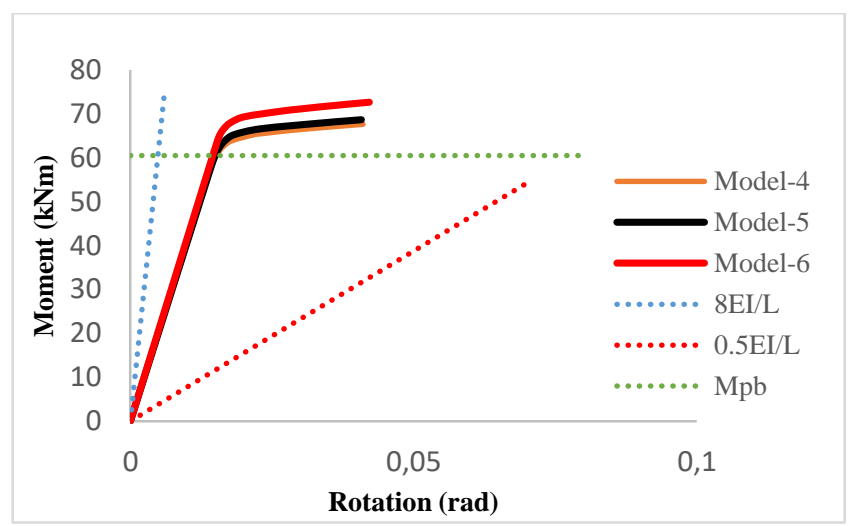

Figure 7. Moment rotation curve of specimens with through plate

Eurocode 3 classifies the joint by initial stuffiness as rigid, semi-rigid, and nominally pinned. A beam to column joint is classified as a fixed connection when the initial stiffness $\left(K_{\text {in }}\right)$ is more significant than $\left(8 \mathrm{EI} / \mathrm{L}_{\mathrm{b}}\right)$, semi-rigid when $\left(8 \mathrm{EI} / \mathrm{L}_{\mathrm{b}}>\mathrm{K}_{\mathrm{in}}>0.5 \mathrm{EI} / \mathrm{L}_{\mathrm{b}}\right)$, and nominally pinned when $\left(\mathrm{K}_{\mathrm{in}}<0.5 \mathrm{EI} / \mathrm{L}_{\mathrm{b}}\right)$. This classification, welding the direct beam to the column or welding the column to the plate (Model-1, Model-2, and Model-3), was classified as nominally pinned. However, including through plates (Model4, Model-5, and Model-6) increased the initial stuffiness, and this connection was classified as a semirigid connection.

\subsection{Cyclic Behavior}

The cyclic behavior of Model-4, Model-5, and Model-6 was numerically studied. Figure 8 shows the comparisons of the cyclic behavior of these models. Formation of a plastic hinge governed all the failure 
models in the beam for all the specimens, and the cyclic behavior was almost identical. However, there was an increase in moment capacity for Model- 6 compared to other models; this results from shear plate length (PL-6). According to the moment rotation curve, the proposed connection exhibited the desirable behavior suggested by the Eurocode- 3 . The rotation capacity was found to be more than 0.04 rad for all through plate connection samples, and also the moment capacity was found to be greater than the plastic moment of the beam (Figure 8 ).

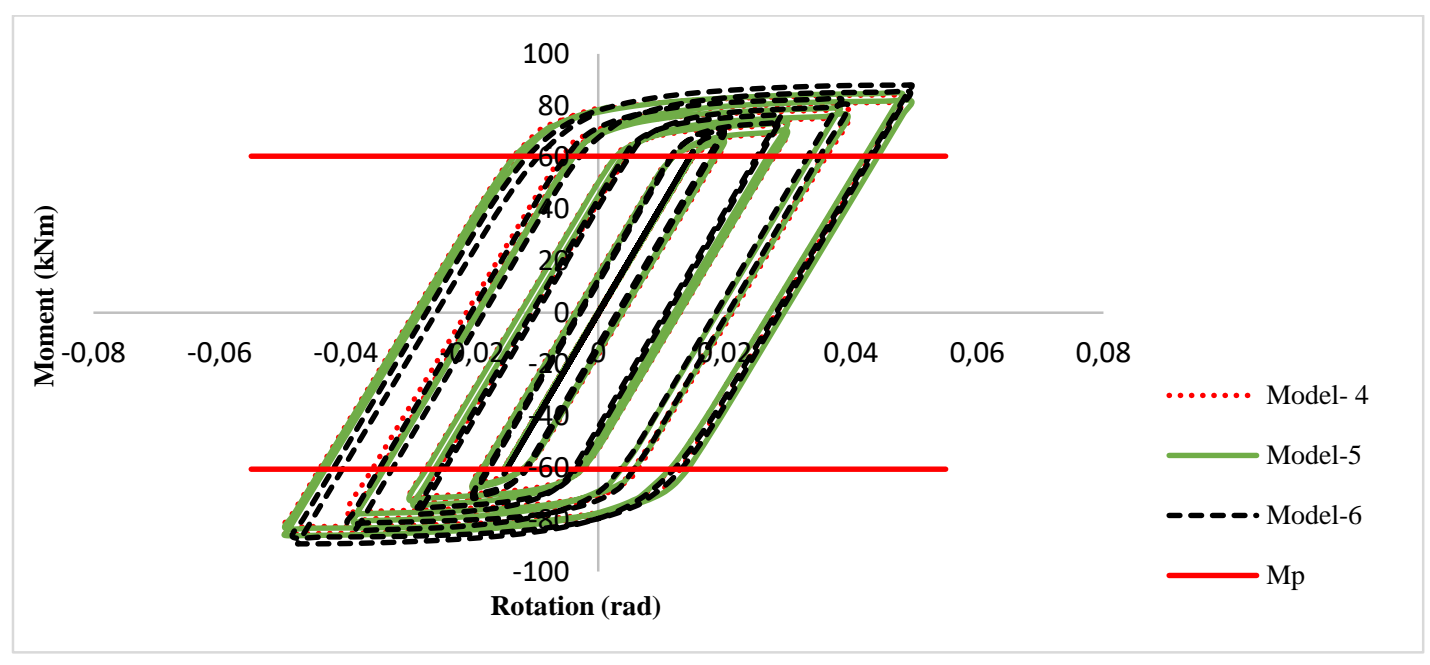

Figure 8. Comparison of cyclic behavior of Model 4,5 and 6

\subsection{Failure Mode}

In ABAQUS, the equivalent plastic strain (PEEQ) describes the accumulation of plastic strain of materials, and this coefficient is generally used to analyze the plasticity development. When the material enters the yielding state, the PEEQ value will be greater than zero and increase as the plastic deformation increases. Therefore the plastic zone conditions in the connection can be distinguished based on the PEEQ contours diagram.

As mentioned, the philosophy of design a strong beam weak column was followed for all connections models. Direct welding the beam to column gives the panel zone's distortion (Figure 9. a,b,d). The plate (Model -3) inclusion moves the plastic hinge away from the panel zone; the maximum PEEQ was found in the beam. Even though the plate increased the capacity of the panel zone, the rotation was still too big. To solve this problem through plates were introduced. Two horizontal plates were to pass into the column. These horizontal plates increased the capacity of the connections (see Figure 9.c). For, through plate connection, the plastic hinge was formed in the beam. In moment resisting frames, the beam's welding directly to the steel tube should not be used.

\section{CONCLUSIONS}

Six specimens were numerically evaluated - each specimen composed of an I-shaped steel beam with the dimensions of IPE-200 connected to the SHS-200 column. For three models, beams were welded directly to the column or the plates, and the remaining three samples were connected through plate connections. The static and cyclic behaviour of these specimens were examined. Through Plate, connections achieved the desirable behavior proposed by the Eurocode-3. The following conclusions can be drawn based on this work

(1) The behaviour of plate connection can be accurately predicted by finite element modeling. Also, FE models present an alternative solution to high-cost experimental studies. 
Twizere and Taşkın / Eskişsehir Technical Univ. J. of Sci. and Tech. A - Appl. Sci. and Eng. 22 (1) - 2021

(2) In moment resisting frames, the beam's welding directly to the steel tube should not be used.

(3) Welding beam directly to the column provides the initial stiffness less than plate connection.

(4) The increase of shear plate length increases the moment capacity of through plate connection.

(5) To reach the beam's plastic capacity, specimens without through plate carry up an excessive rotation.

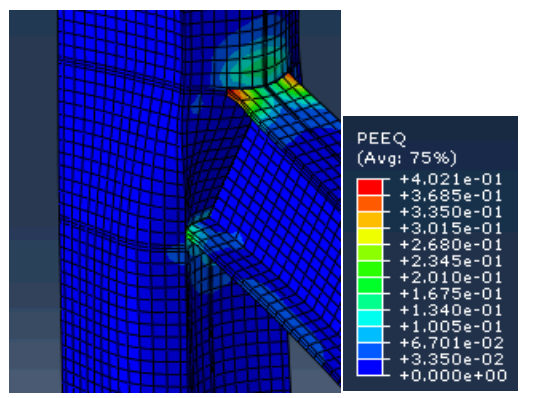

a)The failure mode of Model-1

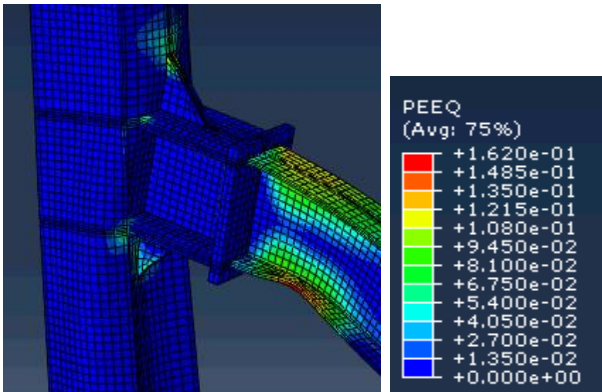

b) The failure mode of Model-3

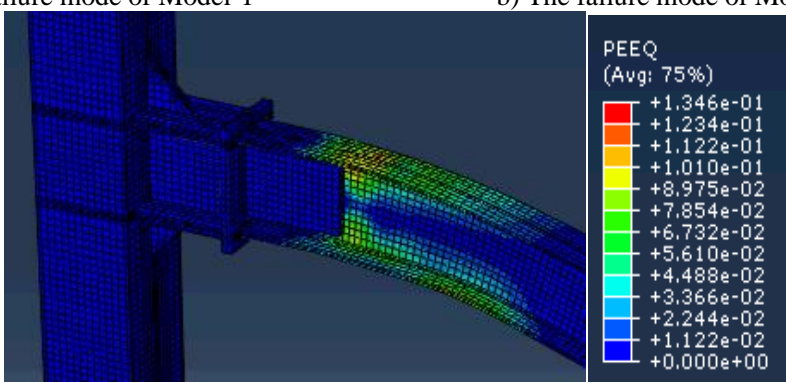

c) The failure mode of Model-6

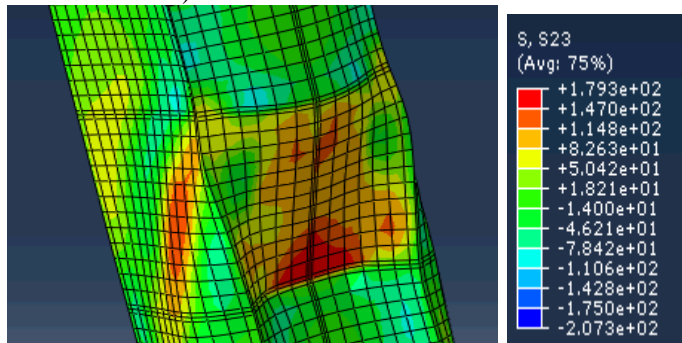

d) Shear stress and column distortion of Model-1

Figure 9. The failure mode

\section{CONFLICT OF INTEREST}

The authors stated that there are no conflicts of interest regarding the publication of this article.

\section{REFERENCES}

[1] Sheet IS, Gunasekaran U, MacRae GA. Experimental investigation of CFT column to steel beam connections under cyclic loading. J Constr Steel Res 2013;86:167-82.

[2] Erfani S, Asnafi AA, Goudarzi A. Connection of I-beam to box-column by a short stub beam. J Constr Steel Res. 2016;127:136-50. 
[3] Ataei A, Bradford MA, Valipour HR. Finite element analysis of HSS semi-rigid composite joints with precast concrete slabs and demountable bolted shear connectors. Finite Elem Anal Des 2016;122:16-38.

[4] Mou B, Bai Y. Experimental investigation on shear behavior of steel beam-to-CFST column connections with irregular panel zone. Eng Struct 2018;168:487-504.

[5] Jiang J, Chen S. Experimental and numerical study of double-through plate connections to CFST column. J Constr Steel Res 2019;153:385-94.

[6] Zhang AL, Zhang H, Jiang ZQ, Li C, Liu XC. Low cycle reciprocating tests of earthquakeresilient prefabricated column-flange beam-column joints with different connection forms. $\mathrm{J}$ Constr Steel Res 2020;164:105771.

[7] Zhou QS, Fu HW, Ding FX, Liu XM, Yu YJ, Wang LP, Yu ZW, Luo L. Seismic behavior of a new through-core connection between concrete-filled steel tubular column and composite beam. J Constr Steel Res 2019;155:107-20.

[8] Dunberry E, LeBlanc D, Redwood RG. Cross-section strength of concrete-filled HSS columns at simple beam connections. Can J Civil Eng 1987;3:408-17.

[9] Alostaz YM, Schneider SP. Analytical behavior of connections to concrete-filled steel tubes. J Constr Steel Res 1996;40:95-127.

[10] Kosteski N, Packer JA. Longitudinal plate and through plate-to-hollow structural section welded connections. J Struct Eng 2003;129:478-86.

[11] Hoang VL, Demonceau JF, Jaspart JP. Resistance of through-plate component in beam-to-column joints with circular hollow columns. J Constr Steel Res 2014;92:79-89.

\section{[12] HTTPS://EUROCODEAPPLIED.COM/DESIGN/EN1993/STEEL-DESIGN-PROPERTIES}

[13] Aydin AC.; Ardalani A, Maali M, Kiliç M. Numeric modeling of innovative semi-rigid connections under cyclic loading. Steel Constr 2020 (accepted for publication). https://onlinelibrary.wiley.com/doi/10.1002/stco.201900037

[14] Pirmoz A, Ahadi P, Farajkhah V. Finite element analysis of extended stiffened end plate link-tocolumn connections. Steel Constr 2016;9:46-57.

[15] Nzabonimpa JD, Hong WK, Kim J. Nonlinear finite element model for the novel mechanical beam-column joints of precast concrete-based frames. Comp \& Struct 2017;189:31-48.

[16] ABAQUS Analysis User's Manual 6.14-2. Dassault Systèmes Simulia Corp., Providence, RI, USA.

[17] Nzabonimpa JD, Hong WK. Structural performance of detachable precast composite column joints with mechanical metal plates. Eng Struct 2018;160:366-82.

[18] Gholami M, Deylami A, Tehranizadeh M. Seismic performance of flange plate connections between steel beams and box columns. J Constr Steel Res 2013;84:36-48. 